\title{
COMPORTAMENTO DE MARACUJAZEIROS (Passiflora spp.) QUANTO À MORTE PREMATURA ${ }^{1}$
}

\author{
GIVANILDO RONCATTO², JOÃO CARLOS DE OLIVEIRA ${ }^{3}$, CARLOS RUGGIERO ${ }^{3}$, GERALDO COSTA NOGUEIRA \\ FILHO ${ }^{2}$, MARIA APARECIDA PESSÔA DA CRUZ CENTURION ${ }^{3}$, FRANCISCO RICARDO FERREIRA ${ }^{4}$
}

\begin{abstract}
RESUMO - Na Universidade Estadual Paulista, Câmpus de Jaboticabal-SP, estudou-se o comportamento de Passifloráceas quanto à morte prematura de plantas, cultivadas em local com histórico da doença. O objetivo do trabalho foi avaliar o comportamento de diversos "acessos" de populações e espécies de maracujazeiros em relação a esta doença, sendo que as plantas resistentes deverão ser utilizadas como porta-enxertos de formas comerciais de maracujá-amarelo (Passiflora edulis Sims f. flavicarpa) e em programas de melhoramento genético. As espécies utilizadas foram $P$. edulis Sims, P. edulis Sims f. flavicarpa Degener, P. nitida H.B.K., P. cincinnata, P. giberti, P. laurifolia, P. morifolia, P. foetida e P. capsularis. Em local com histórico da doença, plantaram-se mudas em número variável e em épocas distintas. A condução das plantas e os tratos culturais foram os recomendados para o maracujá-amarelo. A morte prematura das plantas ocorreu entre dois meses e dois anos da cultura no campo. P. giberti e P. nitida mostraram-se resistente à doença, independentemente do local de origem. Entre os demais "acessos", não se encontraram fontes promissoras de resistência. Entretanto, novos "acessos" e novas espécies deverão ser estudadas na busca da resistência.
\end{abstract}

Termo para indexação: maracujá, melhormento, resistência.

\section{BEHAVIOR OF PASSIONFRUIT (Passiflora spp.)IN RELATION TO PREMATURE DEATH OF PLANTS}

ABSTRACT - The behavior of passionfruit, cultivated in sites with disease history, as to premature death, was researched at Universidade Estadual Paulista, Campus of Jaboticabal, SP. The purpose of the research was to evaluate the behavior of acesses and passionfruit species related to this disease, whereas resistant plants are to be used as yellow passionfruit rootstocks, as well as in breeding programs. The species $P$. edulis Sims, $P$. edulis Sims f. flavicarpa Degener, P. nitida H.B.K., P. cincinnata, P. giberti, P. laurifolia, P. morifolia, P. foetida, P. capsularis were used. In a site with a known record of the disease, the plants were planted in a variable number and at distinct times. Plant conduction was done as recommended for yellow passionfruit. The premature death of the plants ocurred somewhere between two months and two years of field culture. $P$. giberti, $P$. nitida were resistant to the disease despite its place of origin. No other promising resistance sources were found among the remaining "acesses". However, new "acesses" and new species should be researched in search of resistance.

Index terms: passionfruit, improvement, resistance.

A cultura do maracujazeiro intensificou-se no Brasil na década de 70 e evoluiu rapidamente, colocando-se entre as principais.

Dentre as doenças, a morte prematura de plantas tem se destacado, causando prejuízos nas lavouras do País. Essa doença, de causa desconhecida, tem sido associada a fungos do solo, como Fusarium oxysporum f. passiflorae, Fusarium solani, Phytophthora spp. e também à bactéria como Xanthomonas axonopodis f. passiflorae. O sintoma observado é a desintegração dos tecidos corticais do colo da planta e das raízes logo após um período de chuvas intensas (Nakamura, 1987).

São José et al. (2000) testaram as espécies $P$. edulis Sims f. flavicarpa Degener, $P$. alata Dryander, $P$. macrocarpa, $P$. giberti, $P$. laurifolia e $P$. foetida em local contaminado com fusariose; observaram que $P$. alata e $P$. giberti apresentaram melhor comportamento em relação à morte provocada por fusariose.

No geral, os sintomas variam, e tentativas de isolamento do agente causal e inoculação não têm sido bem-sucedidas na reprodução dos sintomas (Oliveira et al., 1986). A planta, antes da morte, tem seu sistema radicular afetado com a entrada do patógeno, evoluindo para um apodrecimento na região do colo e, conseqüentemente, a decomposição do tronco pela destruição da casca e vasos liberianos. A translocação da seiva é interrompida, causando murcha repentina, de forma que as plantas morrem, sendo que as folhas e frutos ficam retidos (São José et al., 1997).

As medidas para o controle da morte prematura são preventivas, e, uma vez afetada pelos patógenos, certamente a planta morrerá, pois não há controle curativo. As principais medidas preventivas são: organizar o pomar na ocasião de sua instalação, evitando áreas encharcadas e cultivadas anteriormente com maracujazeiro; efetuar o plantio o mais superficial possível, visando à aeração do colo e das raízes; controlar formigas e plantas daninhas, evitando injúrias na casca; evitar irrigação excessiva, e efetuar adubações equilibradas (São José $e t$ al., 1997).

A aplicação de defensivos químicos não tem sido eficiente na solução do problema da morte prematura de plantas (Landgraff, 1978; Melo et al., 1990; Torres Filho \& Ponte, 1994). A enxertia de maracujáamarelo, em porta-enxerto resistente, pode viabilizar esta técnica bastante promissora (Menezes et al., 1994).

Com o surgimento de novas áreas de cultivo e a expansão da cultura, observou-se o aparecimento de diversos problemas fitossanitários, causados por fungos, bactérias e vírus. Isso acarretou a redução da vida útil do maracujazeiro, tornando essa cultura itinerante, ou seja, a cultura passou a diminuir seu tempo de permanência numa determinada área. No princípio, a vida útil da cultura era de cinco a seis anos; atualmente, os pomares são renovados a cada dois anos ou mesmo anualmente (Ruggiero, 1996).

Considerando que na América do Sul, e em particular no Brasil, ocorrem muitas espécies e subespécies de Passiflora, o presente trabalho teve por objetivo a avaliação do comportamento de diversos "acessos" de populações e espécies de maracujazeiros quanto à morte prematura de plantas. As plantas resistentes deverão ser utilizadas como portaenxertos do maracujá-amarelo e em programas de melhoramento genético.

$\mathrm{O}$ experimento foi conduzido na área experimental da Universidade Estadual Paulista - Câmpus de Jaboticabal-SP, em área contaminada com o(s) agente(s) fitopatogênico(s) desconhecido(s), responsáveis pela morte prematura de plantas, onde se efetuou o plantio definitivo de Passifloráceas, conforme relação apresentada nas Tabelas 1 e 2 .

O plantio definitivo foi efetuado a partir 1996 até início de 1999, em épocas diferentes, pois fazia-se o plantio com mudas disponíveis na

\footnotetext{
${ }^{1}$ (Trabalho 057/2004). Recebido: 16/04/2004. Aceito para publicação: 10/12/2004.

${ }^{2}$ Doutorando em Agronomia, Faculdade de Ciências Agrárias e Veterinárias - campus de Jaboticabal, Rodovia de Acesso Prof. Paulo Donato Castellane km05 s/n, cep 14884 -900. , Jaboticabal-SP, E-mail: givanildoroncatto@ig.com.br.

${ }_{3}^{3}$ Professores do Departamento de Produção Vegetal da FCAV/UNESP, E-mail: fitotec@ fcav.unesp.br

${ }^{4}$ Eng. Agrônomo, Doutor, Pesquisador do Cenargen-Embrapa, E-mail: fricardo@cenargen.embrapa.br
} 
TABELA 1 - Período do plantio ao surgimento de plantas com morte prematura de espécies de Passiflora cultivadas em local com histórico da doença. Jaboticabal - SP, 1996-1999.

\begin{tabular}{|c|c|c|c|c|}
\hline Espécie/cultivar & Data de plantio & Data de morte* & Período de vida (dias) & Observações \\
\hline P. edulis f. flavicarpa cv. Maguary & $1^{\circ}-04-96$ & $05-12-97$ & 653 & Amarelo graúdo \\
\hline P. edulis (biblioteca) & $28-05-97$ & $17-12-97$ & 203 & P. edulis \\
\hline P. edulis (biblioteca) & $28-05-97$ & $17-12-97$ & 203 & \\
\hline P. edulis (sem identificação) & & $17-12-97$ & & \\
\hline Roxinho do Chile-Urussanga & $18-08-97$ & $17-12-97$ & 121 & P. edulis \\
\hline Roxinho do Chile-Urussanga & $18-08-97$ & $17-12-97$ & 121 & P. edulis \\
\hline IAC & $22-09-97$ & $17-12-97$ & 86 & P. edulis \\
\hline IAC & $22-09-97$ & $17-12-97$ & 86 & P. edulis \\
\hline BRA 2747 & $22-09-97$ & $17-12-97$ & 86 & P. edulis \\
\hline BRA 2961 & $22-09-97$ & $17-12-97$ & 86 & P. edulis \\
\hline P. edulis ${ }_{2}$ vs. P. alata & $11-12-97$ & $05-02-98$ & 67 & \\
\hline IAC-7 & $22-12-98$ & $19-02-99$ & 59 & P. edulis \\
\hline IAC-7 & $22-12-98$ & $19-02-99$ & 59 & P. edulis \\
\hline
\end{tabular}

* Data de constatação de morte prematura de plantas

TABELA 2 - Comportamento de espécies de Passiflora silvestre e cultivadas em local com histórico de morte prematura de plantas. Jaboticabal-SP. Período de 1996-1999.

\begin{tabular}{|c|c|c|c|}
\hline Espécie/cultivar & Origem & № de plantas & Plantas mortas $(\%)$ \\
\hline P. edulis f. flavicarpa (amarelo) & Amazonas & 08 & 100 \\
\hline P. giberti & Cenargem & 100 & 0 \\
\hline P. giberti & Piedade - SP & 01 & 0 \\
\hline P. giberti & Sacramento - MG & 03 & 0 \\
\hline P. giberti & Cuiabá - MT & 10 & 0 \\
\hline P. morifolia* & Rio de Janeiro - RJ & 10 & 50 \\
\hline P. edulis - IAC 7 & Campinas - SP & 10 & 100 \\
\hline P. edulis - IAC 5 & Campinas - SP & 10 & 100 \\
\hline P. laurifolia & Maranhão & 20 & 95 \\
\hline Roxinho do Kenia & Cenargen & 20 & 100 \\
\hline Kenia vs. P. edulis & Jaboticabal - SP & 20 & 100 \\
\hline BRA 2810 (Kenia vs. Amarelo) & Cenargen & 03 & 100 \\
\hline BRA 2801 & Cenargen & 03 & 100 \\
\hline BRA 2763 & Cenargen & 03 & 100 \\
\hline BRA 2747 & Cenargen & 02 & 100 \\
\hline BRA 2721 & Cenargen & 02 & 100 \\
\hline BRA 2691 & Cenargen & 02 & 100 \\
\hline BRA 2739 & Cenargen & 03 & 100 \\
\hline IAC (amarelo) & Campinas - SP & 13 & 100 \\
\hline Roxinho do Chile & Urussanga - SC & 09 & 100 \\
\hline P. cincinnata - BRA 2658 & Cenargen & 02 & 100 \\
\hline P. nitida - Acesso 01 & Amazonas & 60 & 0 \\
\hline P. nitid $a-$ Acesso 02 & Campinas - SP & 08 & 0 \\
\hline P. capsularis & Torres $-\mathrm{RS}$ & 06 & 50 \\
\hline P. capsularis & Piracicaba - SP & 06 & 50 \\
\hline P. capsularis & Jundiaí - SP & 06 & 50 \\
\hline Roxinho silvestre & Torres - RS & 10 & 100 \\
\hline Roxinho silvestre & Lavras - MG & 10 & 100 \\
\hline P. cincinnata & EECB/Bebedouro - SP & 5 & 100 \\
\hline P. cincinnata & Correntes - PI & 20 & 50 \\
\hline P. foetida & Vitória da Conquista - BA & 10 & 100 \\
\hline
\end{tabular}

* Espécie australiana

Há relatos dessa espécie vegetando naturalmente na Mata Atlântica. (Informação pessoal do Sr. Mauro Peixoto www.brazilplants.com) 
época. O preparo da cova, adubações, capinas, condução das plantas e tratamentos fitossanitários foram efetuados de acordo com Ruggiero (1996).

As avaliações da resistência das plantas foram efetuadas em visitas constantes ao pomar e considerou-se como morte prematura de plantas aquelas plantas que apresentaram sintomas característicos.

Inicialmente, as plantas que pereciam, apresentavam uma perda na turgescência da parte aérea, visível nos brotos novos, evoluindo para toda a planta e, 7 a 10 dias após, as folhas apresentavam coloração marrom. Quando podadas, não brotavam mais, ao passo que, em outras situações, normalmente as plantas brotariam. Em plantas adultas, em alguns casos, observou-se um entumescimento na região do colo, com formação de tecido esponjoso, macio ao pressionar com os dedos, sendo que a casca se soltava facilmente do lenho.

Observaram-se ainda a ocorrência de apodrecimento radicular, a destruição das radicelas e o enegrecimento intensivo dos vasos liberianos do caule.

$\mathrm{Na}$ Tabela 1, são apresentados os dados referentes às informações sobre as espécies cultivares, data de plantio, data da constatação da morte precoce das plantas e local de origem do material genético. Analisando-se o período de sobrevida da planta, verifica-se que a morte prematura começa a manifestar-se após dois meses de plantio; entretanto, plantas de origem semelhante conseguem sobreviver. Melo et al. (1990) constataram que, após quatro meses de idade, as plantas iniciaram a morte, após suceder um período chuvoso.

Na Tabela 2, estão representados o número de mudas plantadas em local com histórico de morte prematura de plantas e a percentagem de plantas que sobreviveram. $P$. giberti mostrou-se resistente à morte precoce, independentemente da origem (acessos: "Piedade"," Sacramento","Pantanal"), fato já observado por Oliveira et al. (1986); Menezes et al. (1994); Melo et al. (1990). Os mesmos autores constataram que as espécies $P$. edulis f. flavicarpa e $P$. cincinnata são suscetíveis à morte prematura de plantas enquanto a $P$. nitida mostrou-se resistente. Por outro lado, Maldonado (1991) verificou suscetibilidade em $P$. alata, $P$. caerulea e $P$. giberti, diferindo dos resultados obtidos por São José et al. (2000).

As variedades cultivadas e silvestres de $P$. edulis foram suscetíveis. A busca de resistência dentro de $P$. edulis (frutos de cor roxa ou cor amarela, cultivados ou silvestres) torna-se muito importante, pois pode viabilizar a obtenção de materiais genéticos resistentes, com potencial comercial e a curto espaço de tempo. Os acessos de $P$. cincinnata mostraram-se suscetíveis à morte prematura de plantas, porém a reação quanto à doença foi diferente dos $P$. edulis, ou seja, apresenta declínio e morte lenta das plantas.

$\mathrm{O}$ acesso de $P$. laurifolia do Estado do Maranhão mostrou-se suscetível, diferentemente do comparado a outras introduções dessa espécie, as quais apresentaram variação pomológica e tolerância à doença.
P. foetida e $P$. morifolia mostraram-se suscetíveis à morte precoce de plantas, entretanto outros acessos de diferentes origens deverão ser avaliados.

Já a espécie $P$. capsularis foi aparentemente suscetível. No entanto, novas avaliações deverão ser efetuadas, pois não se adaptou no cultivo a pleno sol, além do pouco vigor apresentado por esta espécie silvestre. Assim, a morte de $50 \%$ das plantas provavelmente não se atribua à morte prematura de plantas, podendo vir a ser material resistente a esta doença.

\section{REFERÊNCIAS}

LANDGRAFF, J.H. Perspectiva da cultura do maracujá no Brasil. In: SIMPÓSIO SOBRE A CULTURA DO MARACUJÁ, 2., 1978. Jaboticabal. Anais... p.2-8.

MALDONADO, J.F.M. Utilização de porta-enxertos do gênero Passiflora para maracujazeiro-amarelo (Passiflora edulis Sims f. flavicarpa Deg.). Revista Brasileira de Fruticultura, Jaboticabal, v.13, n.2, p.51-54, 1991.

MELO, M.B. de; BATISTA, F.A.S.; SILVA, L.M.S.; TRINDADE, J. Controle da podridão das raízes do maracujazeiro Passiflora edulis f. flavicaparpa Deg. Revista Brasileira de Fruticultura, Jaboticabal, v.12, n.2, p.7-12, 1990.

MENEZES, J.M.T.; OLIVEIRA, J.C. de; RUGGIERO, C.; BANZATTO, D. A. Avaliação da taxa de pegamento de enxertos de maracujá-amarelo sobre espécies tolerantes à "morte prematura de plantas". Científica, São Paulo, v.22, n.1, p.95-104, 1994.

NAKAMURA, K. Murcha e morte. In: RUGGIERO, C. Maracujá. Ribeirão Preto: Legis Summa, 1987. p.160-61

OLIVEIRA, J.C.; NAKAMURA, K.; RUGGIERO, C.; FERREIRA F.R. Determinação de fontes de resistência em Passifloraceas quanto à morte prematura de plantas. In: CONGRESSO BRASILEIRO DE FRUTICULTURA, 8., 1986, Brasília, Anais... v.2, p.403-408.

RUGGIERO, C. (Coord.). Maracujá para exportação: aspectos técnicos. Brasília: EMBRAPA-SPI, 1996. p.11-29

SÃO JOSÉ, A.R.; BRUCKNER, C.H.; MANICA, I.; HOFFMANN, M. Maracujá: temas selecionados(1) melhoramento, morte prematura, polinização, taxionomia. Porto Alegre: Cinco Continentes, 1997. p.4757.

SÃO JOSÉ, A.R.; SANTOS, A.; SILVA, A.C. da; BOMFIM, M.P.; MORAIS, O.M.; ATAIIDE, E.M.; BARBOSA, N.M.L. Fusariose no semi-árido. In: CONGRESSO BRASILEIRO DE FRUTICULTURA, 16., 2000, Anais... p.470.

TORRES FILHO, J.; PONTE, J.J. da. Estudo sobre o controle da bacteriose ou "morte precoce" (Xanthomonas campestris pv. passiflorae) do maracujá-amarelo (Passiflora edulis f. flavicarpa). Fitopatologia Brasileira, Brasília, v.19, n 3.1, p.34-38, 1994. 